\title{
Have Gender Gaps in Insurance Coverage and Access to Care Narrowed Under Health Reform? Findings from Massachusetts
}

\author{
Sharon K. Long* \\ University of Minnesota \\ School of Public Health \\ Division of Health Policy and Management \\ 2221 University Avenue SE, Suite 345 \\ Minneapolis, MN 55414 \\ 612-624-1566 (phone) \\ 612-624-1493 (fax) \\ slong@umn.edu \\ Karen Stockley \\ The Urban Institute \\ 2100 M Street, NW \\ Washington, DC 20037 \\ 202-261-5667 (phone) \\ 202-223-1149 (fax) \\ kstockley@urban.org \\ Shanna Shulman \\ Blue Cross Blue Shield of Massachusetts Foundation \\ Landmark Center \\ 401 Park Drive \\ Boston, MA 02215 \\ 617-246-5078 (phone) \\ 617-246-3992 (fax) \\ shanna.shulman@bcbsma.com
}

Session: Gender and Social Policy

Chair: Shirley Johnson-Lans (Vassar College)

Discussants: Anne Winkler (University of Missouri-St. Louis), Ann Mari May (University of Nebraska-Lincoln), Tracy Falba (Duke University), Paul Glewwe (University of Minnesota) *Corresponding author. 


\section{Have Gender Gaps in Insurance Coverage and Access to Care Narrowed Under Health Reform? \\ Findings from Massachusetts}

\section{Sharon K. Long \\ Karen Stockley \\ Shanna Shulman ${ }^{*}$}

\section{Introduction}

As a result of its landmark 2006 health reform legislation, Massachusetts has achieved near universal health insurance coverage, along with significant gains in access to and use of care and in the affordability of care (Sharon K. Long and Karen Stockley 2010). Improvements have been documented for the population as a whole, as well as for vulnerable subgroups including lower-income adults, racial and ethnic minorities, and adults with chronic health conditions. This paper examines the impacts of health reform on gender disparities in Massachusetts. We focus on the impacts of health reform on disparities in insurance coverage, access to and use of health care, and the affordability of health care between fall 2006, just prior to the implementation of key elements of health reform in the state, and fall 2009, the most recent year for which postreform data are currently available.

\footnotetext{
* Long: University of Minnesota, School of Public Health, Division of Health Policy and Management, 2221 University Avenue SE, Suite 345, Minneapolis, MN 55414 (slong@umn.edu); Stockley: Urban Institute, 2100 M Street, NW, Washington, DC 20037 (kstockley@urban.org); Shulman: Blue Cross Blue Shield of Massachusetts Foundation, Landmark Center, 401 Park Drive, Boston, MA 02215 (shanna.shulman@bcbsma.com). This work was supported by the Blue Cross Blue Shield of Massachusetts Foundation.
} 
Gender differences in health care needs and use of health care are well established. Women tend to have a greater need for health care services than men, in large part due to reproductive health needs at younger ages and greater incidence of chronic conditions at older ages (Cara J. James et al. 2009). While women tend to have higher rates of insurance coverage than men, largely due to the availability of Medicaid coverage for pregnant women and the families of low-income children, they are more likely to forego needed care because of costs (Sheila D. Rustgi, Michelle M. Doty, and Sara R. Collins 2010). Coupled with their greater health needs, women also spend a greater share of their income on medical care, and are more likely than men to struggle with medical bills or debt (Rustgi, Doty, and Collins 2010). Women also typically earn less than men (U.S. Census Bureau 2010a), which can make it more difficult for them to afford needed care. In addition to their greater health care needs, other potential reasons women use more care than men could be preferences for greater service use for a given level of need, or a tendency to use more care due to their higher levels of insurance coverage. Massachusetts' push toward universal coverage provides an opportunity to understand how gender differences in access, use, and affordability of health care change when insurance coverage levels become more equalized between the sexes. While we would also like to know the impact of having health insurance coverage on women's access, use, and affordability of care relative to men's, comparing the outcomes of insured men and women is problematic because the decision to obtain insurance coverage is endogenous and likely reflects health care needs and anticipated demand for health care, which tend to be higher among women. Examining the changes in access and use associated with the coverage expansions after health reform for all men and women in the state will tell us the aggregate impact of health reform on gender 
disparities, as well as give us some insight into the effects of insurance coverage on access, use, and affordability of care for men and women.

\section{Data and Methods}

We use data from the Massachusetts Health Reform Survey to examine changes over time in insurance coverage, access to and use of health care, and affordability of care for women and men aged 18 to 64 years. The surveys, which have been conducted every fall since 2006, are based on stratified random samples, with oversamples of the low- and moderate-income and uninsured adults who were the primary focus of many elements of Massachusetts' health reform initiative (Sharon K. Long 2009).

Our analytic approach compares gender differences in outcomes for cross-sectional samples of men and women in fall 2006, just prior to the implementation of key elements of health reform, and fall 2009, the most recent post-reform year for which data are available. ${ }^{1}$ Under this pre-post framework, changes in gender differences between fall 2006 and fall 2009 are attributed to the state's reform efforts. We report estimates based on multivariate regression models that control for demographic, health and disability, and socioeconomic characteristics, as well as region fixed effects. ${ }^{2}$ In the models of gender differences in the pre- and post-reform periods, we use data from only the specific pre- or post-reform year (2006 or 2009, respectively). In testing whether gender differences changed over the study period, we estimate models using data for all four years of the survey (fall 2006, fall 2007, fall 2008 and fall 2009) to test if the gender difference in 2009 was different from the gender difference in $2006 .{ }^{3}$ We estimate

\footnotetext{
${ }^{1}$ The fall 2006 survey was fielded as the Commonwealth Care program was beginning for adults with family income under $100 \%$ of the federal poverty level; however, enrollment started slowly.

${ }^{2}$ Appendix Tables 1 and 2 report on the characteristics of the men and women in fall 2006 and fall 2009.

${ }^{3}$ Including data from 2007 and 2008 helps stabilize the coefficient estimates on the control variables, and is consistent with models used in earlier work.
} 
separate models for all non-elderly adults and for subgroups based on age (18-45 and 46-64) to determine if gender disparities and changes in gender disparities differed between younger and older adults. In presenting the estimates of the impacts of health reform, we report on the actual outcomes for women in fall 2006 and fall 2009 and the regression-adjusted differences from men in the same age group. For ease of comparison across models, we estimate linear probability models. We control for the complex design of the sample using the survey data analysis procedures (svy) in Stata 11 (StataCorp. 2009).

The primary concern with this type of analysis is that other factors beyond health reform changed differentially for women and men over the study period, which could bias the estimates of the impacts of health reform on gender disparities. For example, if the recession that began in December 2007 impacted women more severely than men, or vice versa, this could impact trends in our outcome variables, biasing our results. The regression models control for socioeconomic factors, including employment status and family income, but other unmeasured socioeconomic factors that may have changed differentially over the period could impact our estimates. Another major change over the study period was the continuing increase in health care costs in the state, a national trend that predates health reform. Again, this would only impact our estimates of the changes in gender disparities if this trend impacted men and women differentially.

\section{Gender Difference Prior to Reform}

Prior to health reform, women were much more likely to have insurance coverage than men, especially younger women relative to younger men (Table 1). This reflects, in part, greater availability of public coverage for women in the state prior to health reform. Women also used care more than men, particularly among younger adults. This is not surprising due to younger women's higher levels of insurance coverage and the reproductive health care needs of women in 
their child-bearing years. Despite their much higher levels of insurance coverage, women were just as likely as men to report unmet need for health care and to have had problems affording care prior to health reform, and older women were significantly more likely to have had problems paying medical bills, suggesting that insurance provided less financial protection for women than men with the same health status and financial resources.

Table 1: Regression-adjusted Gender Differences in Health Insurance Coverage and Health Care Access, Use, and Costs for Adults 18 to 64 Prior to Health Reform, Fall 2006

\begin{tabular}{|c|c|c|c|c|}
\hline & \multicolumn{2}{|c|}{ Ages 18-64 } & \multirow{2}{*}{$\begin{array}{l}\text { Women-Men } \\
\text { Difference for } \\
\text { Ages } 18 \text { to } 45\end{array}$} & \multirow{2}{*}{$\begin{array}{l}\text { Women-Men } \\
\text { Difference for } \\
\text { Ages } 46 \text { to } 64\end{array}$} \\
\hline & Women & $\begin{array}{l}\text { Difference } \\
\text { from Men }\end{array}$ & & \\
\hline \multicolumn{5}{|l|}{ Insurance coverage } \\
\hline Any insurance coverage & 91.1 & $7.8 * * *$ & $11.5 * * *$ & $2.5 *$ \\
\hline ESI coverage & 68.0 & $5.4 * * *$ & $5.9 * *$ & $5.4 * *$ \\
\hline Public or other coverage & 23.1 & 2.4 & $5.6 * *$ & -2.9 \\
\hline \multicolumn{5}{|l|}{ Health care access and use in past 12 months } \\
\hline Has a usual source of care (excluding the ED) & 90.0 & $5.4 * * *$ & $8.3 * * *$ & 1.4 \\
\hline Any doctor visit & 84.7 & $6.1 * * *$ & $7.2 * *$ & $5.0 *$ \\
\hline Any specialist visit & 56.4 & $10.4 * * *$ & $11.3 * * *$ & $9.0 * *$ \\
\hline Any dental care visit & 72.0 & $9.1 * * *$ & $8.8 * * *$ & $8.2 * * *$ \\
\hline Took any prescription drugs & 62.0 & $10.2 * * *$ & $14.1 * * *$ & $5.7 *$ \\
\hline Did not get needed care for any reason & 27.4 & 3.5 & 2.0 & 4.9 \\
\hline \multicolumn{5}{|l|}{ Health care costs in past 12 months } \\
\hline Had problems paying medical bills & 22.3 & 2.8 & 0.4 & $6.5 * *$ \\
\hline Did not get needed care because of costs & 17.9 & 1.7 & 1.3 & 2.9 \\
\hline
\end{tabular}

Source: 2006 Massachusetts Health Reform Survey (N=2,925 for adults 18-64; N=1,476 for adults 18 to $45 ; \mathrm{N}=1,445$ for adults 46 to 64 )

ED is emergency department

${ }^{*}\left({ }^{* *}\right)\left({ }^{* *}\right)$ Women-men difference is significantly different from zero at the $.10(.05)(.01)$ level, twotailed test.

\section{Gender Differences after Reform}

Under health reform, both men and women experienced gains in coverage, access to and use of care, and the affordability of care (Tables 2 and 3). Gains in coverage, access, and use were higher for younger women and younger men relative to older women and older men, 
respectively. Health reform narrowed the gap between men and women significantly in terms of coverage, as more men (particularly younger men) gained coverage relative to women (Table 4). Gender differences in doctor visits and prescription drug use for older adults were no longer significant post-reform. Overall, older women continued to use more care than men under health reform, although the differences were smaller than prior to reform. Women experienced more problems affording health care after reform, particularly younger women compared to younger men. Younger women were 5.8 percentage points more likely to experience unmet need due to cost and 5.3 percentage points more likely to have problems paying medical bills relative to younger men in fall 2009. Given that younger women were 4.5 percentage points more likely to have insurance coverage, this is indicative of worse financial protection of insurance coverage for younger women relative to younger men.

Table 2: Regression-adjusted Estimates of Changes in Health Insurance Coverage and Health Care Access, Use, and Costs for Women 18 to 64 Under Health Reform, Fall 2006 to Fall 2009

\begin{tabular}{|c|c|c|c|c|}
\hline & \multicolumn{2}{|c|}{ Ages 18-64 } & \multirow{2}{*}{$\begin{array}{c}\text { 2006-2009 } \\
\text { Change for } \\
\text { Ages } 18 \text { to } 45\end{array}$} & \multirow{2}{*}{$\begin{array}{c}\text { 2006-2009 } \\
\text { Change for } \\
\text { Ages } 46 \text { to } 65\end{array}$} \\
\hline & 2006 & $\begin{array}{c}\text { 2006-2009 } \\
\text { Change }\end{array}$ & & \\
\hline \multicolumn{5}{|l|}{ Insurance coverage } \\
\hline Any insurance coverage & 91.4 & $5.7 * * *$ & $6.4 * * *$ & $4.9 * * *$ \\
\hline ESI coverage & 67.1 & 1.6 & 2.7 & 0.5 \\
\hline Public or other coverage & 24.3 & $4.1 * *$ & 3.7 & $4.5 * * *$ \\
\hline \multicolumn{5}{|l|}{ Health care access and use in past 12 months } \\
\hline Has a usual source of care (excluding the ED) & 90.3 & $2.5 * *$ & 2.5 & $2.6 *$ \\
\hline Any doctor visit & 84.8 & $5.8 * * *$ & $9.6 * * *$ & 1.1 \\
\hline Any specialist visit & 56.6 & 3.4 & 4.7 & 2.3 \\
\hline Any dental care visit & 72.7 & $6.4 * * *$ & $8.6 * * *$ & 2.8 \\
\hline Took any prescription drugs & 61.8 & 2.3 & 1.7 & 3.4 \\
\hline Did not get needed care for any reason & 26.9 & $-5.7 * * *$ & $-5.9 *$ & $-5.5 * *$ \\
\hline \multicolumn{5}{|l|}{ Health care costs in past 12 months } \\
\hline Had problems paying medical bills & 20.9 & 1.3 & 2.7 & -0.9 \\
\hline Did not get needed care because of costs & 17.2 & $-3.7 * *$ & -3.7 & $-3.4 *$ \\
\hline
\end{tabular}


Table 3: Regression-adjusted Estimates of Changes in Health Insurance Coverage and Health Care Access, Use, and Costs for Men 18 to 64 Under Health Reform, Fall 2006 to Fall 2009

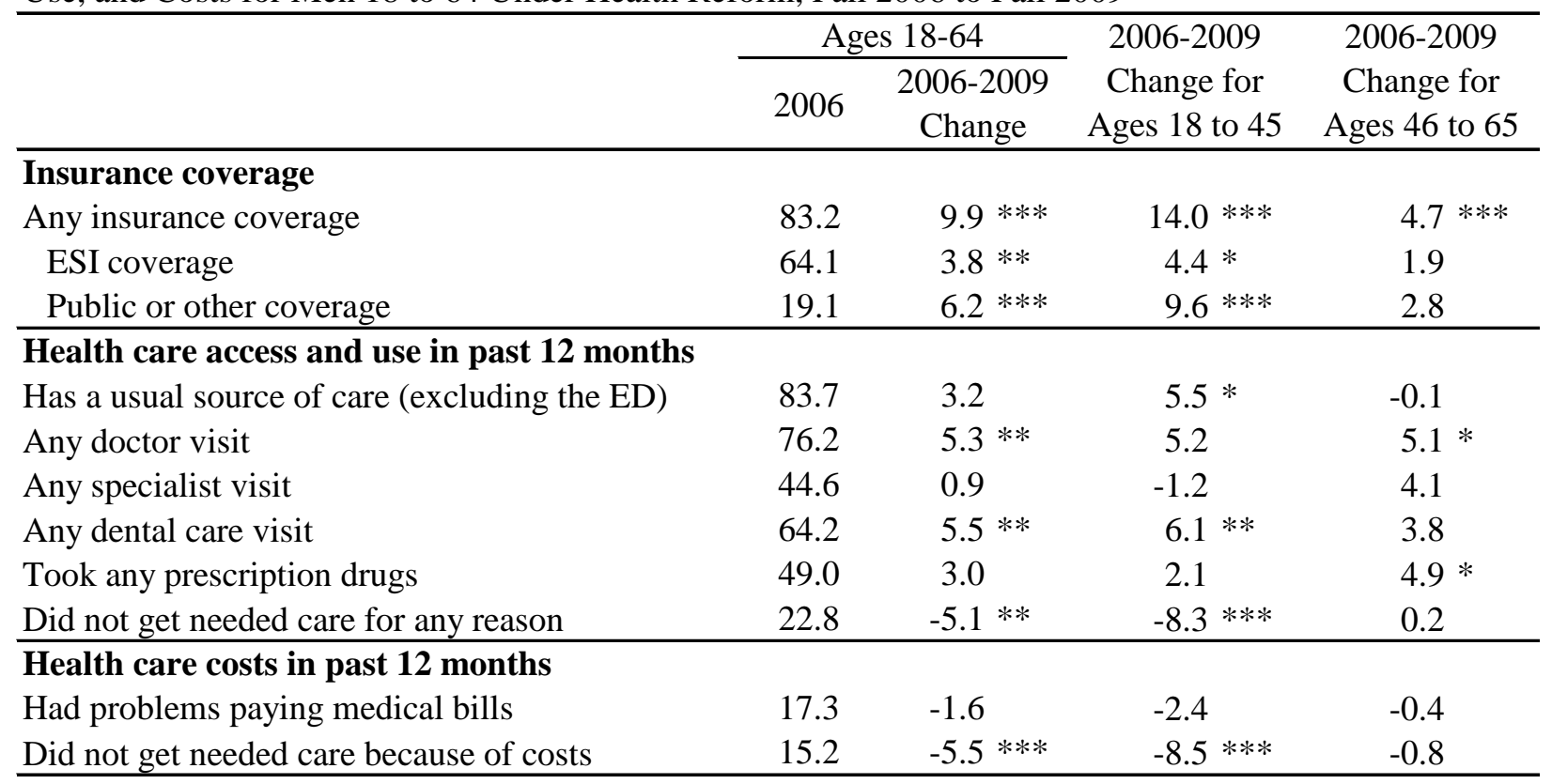

Source: 2006-2009 Massachusetts Health Reform Surveys (N=5,265 for men 18 to 64; 2,512 for men 18 to 45 ; 2,741 for men 46 to 64$)$

$*(* *)(* * *)$ Change is significantly different from zero at the $.10(.05)(.01)$ level, two-tailed test.

V. Conclusions and Lessons for National Reform

Both men and women gained under health reform in Massachusetts. However, despite higher levels of health insurance coverage in 2009, women were more likely to report unmet need for health care and problems affording care than men, particularly among younger adults. On average, insurance coverage does a better job at protecting the health and financial circumstances of men than of women.

Both men and women gained under health reform in Massachusetts. Insurance coverage, in particular, is at nearly $100 \%$ for women, and men have made strides towards achieving a similar level of coverage. The financial effect of these coverage gains, however, appears to have inconsistent effects in women and men. Whereas increased levels of coverage have reduced 
unmet need due to costs both for women and men, gender gaps in the affordability of care have widened for younger adults. Specifically, coverage seems to have conferred stronger financial protections for men than women, perhaps reflecting that coverage does not guarantee affordability of care, particularly among a population such as women with their higher health care needs (reflecting reproductive health needs and higher chronic disease incidence) and, reflecting that, at least in part, higher health care utilization. As Massachusetts (and the nation) turns it attention towards cost containment in its next wave of reform, issues of how to ensure affordability of care for those with insurance coverage will be key to the discussion.

Table 4: Regression-adjusted Gender Differences in Health Insurance Coverage and Health Care Access, Use, and Costs for Adults 18 to 64 After Health Reform, Fall 2009

\begin{tabular}{|c|c|c|c|c|}
\hline & \multicolumn{2}{|c|}{ Ages 18-64 } & \multirow{2}{*}{$\begin{array}{l}\text { Women-Men } \\
\text { Difference for } \\
\text { Ages } 18 \text { to } 45\end{array}$} & \multirow{2}{*}{$\begin{array}{l}\text { Women-Men } \\
\text { Difference for } \\
\text { Ages } 46 \text { to } 64\end{array}$} \\
\hline & Women & $\begin{array}{l}\text { Difference } \\
\text { from Men }\end{array}$ & & \\
\hline \multicolumn{5}{|l|}{ Insurance coverage } \\
\hline Any insurance coverage & 97.1 & $3.7 * * *$ & $4.5 * * *$ & $2.3 * * *$ \\
\hline ESI coverage & 68.7 & 3.2 & 2.9 & $5.1 * * *$ \\
\hline Public or other coverage & 28.4 & 0.5 & 1.6 & -2.8 \\
\hline \multicolumn{5}{|l|}{ Health care access and use in past 12 months } \\
\hline Has a usual source of care (excluding the ED) & 92.8 & $5.6 * * *$ & $6.3 * * *$ & $4.9 * * *$ \\
\hline Any doctor visit & 90.7 & $8.0 * * *$ & $13.2 * * *$ & 0.5 \\
\hline Any specialist visit & 60.1 & $14.4 * * *$ & $19.6 * * *$ & $7.2 *$ \\
\hline Any dental care visit & 79.1 & $9.2 * * *$ & $9.9 * * *$ & $8.1 * * *$ \\
\hline Took any prescription drugs & 64.1 & $10.4 * * *$ & $17.9 * * *$ & -0.1 \\
\hline Did not get needed care for any reason & 21.2 & 1.3 & $4.2 *$ & -2.3 \\
\hline \multicolumn{5}{|l|}{ Health care costs in past 12 months } \\
\hline Had problems paying medical bills & 22.2 & $4.4 * *$ & $5.3 * *$ & 3.4 \\
\hline Did not get needed care because of costs & 13.6 & $2.3 * *$ & $5.8 * * *$ & -1.4 \\
\hline
\end{tabular}

Source: 2009 Massachusetts Health Reform Survey (N=3,041 for adults 18-64; N=1,297 for adults 18 to 45; N=1,735 for adults 46 to 64) for estimates of 2009 gender differences; 2006-2009 Massachusetts Health Reform Survey $(\mathrm{N}=13,150)$ for estimates of changes in gender differences over time.

ED is emergency department $\left.{ }^{* *}\right)\left({ }^{* *}\right)$ Women-men difference is significantly different from zero at the $.10(.05)(.01)$ level, twotailed test.

Bold indicates the women-men difference in fall 2009 is significantly different from the women-men difference in fall 2006 at at least the .10 level, two-tailed test. 
The findings on gender differences in Massachusetts have implications for national health reform. In 2009, 18.4\% of men were uninsured, compared to $15.0 \%$ of women nationally (U.S. Census Bureau 2010b). The Medicaid expansions and subsidies to purchase coverage mandated by the new Patient Protection and Affordable Care Act (ACA) should narrow the national gender gap in insurance coverage. However, state differences in coverage standards of care suggest that there may be greater disparities in access to care in other parts of the country. Unlike many other states, Massachusetts has long had high coverage standards for contraceptives and screening services for women (Tracey Hyams and Laura Cohen 2010). Understanding why women have more difficulties obtaining the care they need and have more difficulties paying for their care is an important direction for future research.

\section{References}

Hyams, Tracey, and Laura Cohen. 2010. “Massachusetts Health Reform: Impact on Women’s Health.” Paper presented at the Massachusetts Health Policy Forum, Boston. http://masshealthpolicyforum.brandeis.edu/forums/Documents/Issue\%20Brief_ConnorCe nter.pdf

James, Cara J., Alina Salganicoff, Megan Thomas, Usha Ranji, Marsha Lillie-Blanton, and Roberta Wyn. 2009. “Putting Women’s Health Care Disparities on the Map: Examining Racial and Ethnic Disparities at the State Level.” http://www.kff.org/minorityhealth/upload/7886.pdf

Long, Sharon K. 2009. "The Massachusetts Health Reform Survey.” http://www.urban.org/url.cfm?ID=411649 
Long, Sharon K., and Karen Stockley. 2010. "Sustaining Health Reform in a Recession: An Update on Massachusetts as of Fall 2009.” Health Affairs, 29(6): 1234-1241.

Rustgi Sheila D., Michelle M. Doty, and Sara R. Collins. 2009 “Women at Risk: Why Many Women are Foregoing Needed Health Care.” http://www.commonwealthfund.org/Content/Publications/IssueBriefs/2009/May/Women-at-Risk.aspx

StataCorp. 2009. Stata Statistical Software: Release 11. College Station, TX: StataCorp LP. U.S. Census Bureau. 2010a. “Historical Income Tables - People, Table P-40: Women's Earnings as a Percentage of Men's Earnings by Race and Hispanic Origin: 1960 to 2009.” Available from: http://www.census.gov/hhes/www/income/data/historical/people/index.html (accessed November 8, 2010)

U.S. Census Bureau. 2010b. “Table HI01: Health Insurance Coverage Status and Type of Coverage by Selected Characteristics: 2009.” Available from: http://www.census.gov/hhes/www/cpstables/032010/health/h01_001.htm (accessed November 8, 2010) 